\title{
The quest for powerful learning environments in higher education
}

\author{
J. A. Slabbert \\ Faculty of Education \\ University of Pretoria \\ Pretoria, South Africa \\ e-mail: jslabbert@up.ac.za \\ D. G. Gouws \\ School of Financial Sciences \\ University of Pretoria \\ Pretoria, South Africa \\ e-mail:daan.gouws@up.ac.za
}

\begin{abstract}
An introductory course in on tertiary level inadvertently sets the scene for the demands of the corresponding profession. Unfortunately, it seems as though these courses do not prepare learners adequately to acquire the demanding professional competences required for professional success. This problem has been a subject of contention especially in accounting education for a very long time amongst practitioners, educators, researchers and professional bodies alike. The article proposes that the fundamental problem is epistemological in nature: The authentic nature and structure (epistemology) of accounting is not reflected and, subsequently, education practices are adopted that does not serve the learner to conquer the challenging demands of the profession accordingly. To arrive at a new paradigm for introductory accounting education, powerful learning environments are suggested as a way to provide competent professionals.
\end{abstract}

\section{INTRODUCTION}

Introductory accounting education has been a subject of contention for a very long time amongst practitioners, educators, researchers and professional bodies alike since the 1960 's. The pivotal problem is summarized by Goldberg $(2001,307)$ when he states that there exists a '.. general failure of the educational process to provide the kind of people capable of meeting the requirements of the rapidly changing world into which they graduate', and this is supported by Gray and McKernan $(2000,66)$. This has prompted the Education Committee of SAICA (South African Institute of Chartered Accountants) with the identification of a desperate need for research into 'The learning of accounting I' (SAICA 2003, 3). The problem, therefore, is fundamentally educational in nature. 


\section{THE PROBLEM}

One way of detecting the causes of these problems, is to identify the underpinning epistemology of the current introductory accounting education practices. Through personal involvement of more than 30 years in at least 3 different higher education institutions simple observation of classroom practices, learning materials used, learner assignments and test and exams, revealed the following major epistemological features of introductory accounting as they are experienced in practice currently.

\section{Problem one: Introductory accounting education is content driven}

Introductory accounting education occupies itself almost entirely by the transfer of content during lectures and other associated restrictive teaching methods (Bedford Report 1986; Bedford and Shenkir 1987; Gouws and Bosua 1997; Claxton 2000; Korthagen 2003). This implies that the content in textbooks is seen as the practical and body of knowledge that the accountant needs to be acquainted with to be part of the fraternity. It means that this knowledge already exists in the form of a product (textbooks and documents) that the learner needs to acquire. For all practical purposes, it means that as soon as the learner has acquired all the content in the textbook(s), he/she has acquired all the knowledge to be an accountant. The purpose of accounting education therefore is to transfer this knowledge from lecturer to learner who then has to regurgitate as much content as possible in various ways (assignments, tests, exams) that would represent competence in accounting. The recycling of existing knowledge in the form of content therefore drives introductory accounting education.

\section{Problem two: Introductory accounting education is prescriptive}

An overwhelming amount of introductory accounting content is of a prescriptive nature: exact procedures to follow, exact formulas to apply, exact entries to make, exact calculations to execute, etcetera (Bedford Report 1986; Gouws 1995; Gray and McKernan 2000) In that sense, introductory accounting education is epistemologically very restrictive, where learners experience unbreachable boundaries, with a right or wrong perspective with no gray areas. Introductory accounting education is driven by instructing learners to almost blindly follow prescribed methods and procedures.

\section{Problem three: Introductory accounting education produces technicians}

The introductory accounting learner undoubtedly needs to be able to follow exact procedures, apply exact formulas, make exact entries, execute exact calculations, etc. However, in essence, such a level of operation represents nothing more than that of a technician as the only 'skill' necessary for an accountant. The major focus of introductory accounting education is teaching learners to follow these restrictive 
prescriptions (Bedford Report 1986; Lucas and Meyer 2003) and do not challenge them with the necessary professional human competences (Huhne, Ehrenreich and Putnam 1997; Mladenovic 2000).

Considering the major causes of problems in accounting education, two very important observations should be noted: The one is that accounting education seems to focus only on transferring knowledge and technical skills to learners to execute accounting functions. Although these accounting functions are in itself part of the essence of accounting, it is the unfortunate elevation of them to the absolute essence that has revealed them as the culprits for causing the problems and the subsequent neglect of other major generic features such as critical thinking, vital decision making and creative problem solving. The second observation relates closely to the previous one in that current accounting education seems to ignore the fact that doing accounting (the discipline of accounting itself) and educating someone to do accounting (the discipline of accounting education: how to facilitate someone to learn how to do accounting), is two completely different disciplines and practices. As can be deduced from the previous paragraph, the problem that needs to be solved is two-fold: The one is to determine the essence of accounting as it manifests in its authentic epistemology in order to know how to educate someone to do accounting as it is reflected in its nature and structure. The other problem is subsequent to the previous one and that is to establish an education paradigm that will maximize authentic learning in introductory accounting education.

\section{RESEARCH METHODOLOGY}

The research methodology that will be adopted which will provide access to both the problems to be solved in the subsequent way that it need to be done, will be the somewhat historical but extremely valuable model of a systems view of problem solving designed by Mitroff, Betz, Pondy, and Sagasti (1974) depicted graphically in Figure 1. The model takes a holistic or systems view of the different variables of scientific activities in problem solving: In this research the problem to solve is how to establish an education paradigm that will maximize authentic learning in introductory accounting education, as mentioned before. As its layout (in Figure 1) reflects, the model has no predefined start or end. This research, however, uses the Mitrof et al. (1974) model as its foundation adopting the following sequence as its particular design (methodology):

(a) Establishing the reality problem situation which has in fact been done in the previous paragraphs;

(b) Constructing a conceptual model which sets out in broad conceptual terms the particular problem that will be solved and specifies the field variables that will be used to define the nature of the problem;

(c) Designing a scientific model as a combination of qualitative logical relationships which links the relevant activities and features of the phenomena;

(d) Proposing a solution to the problem in a real life situation. 


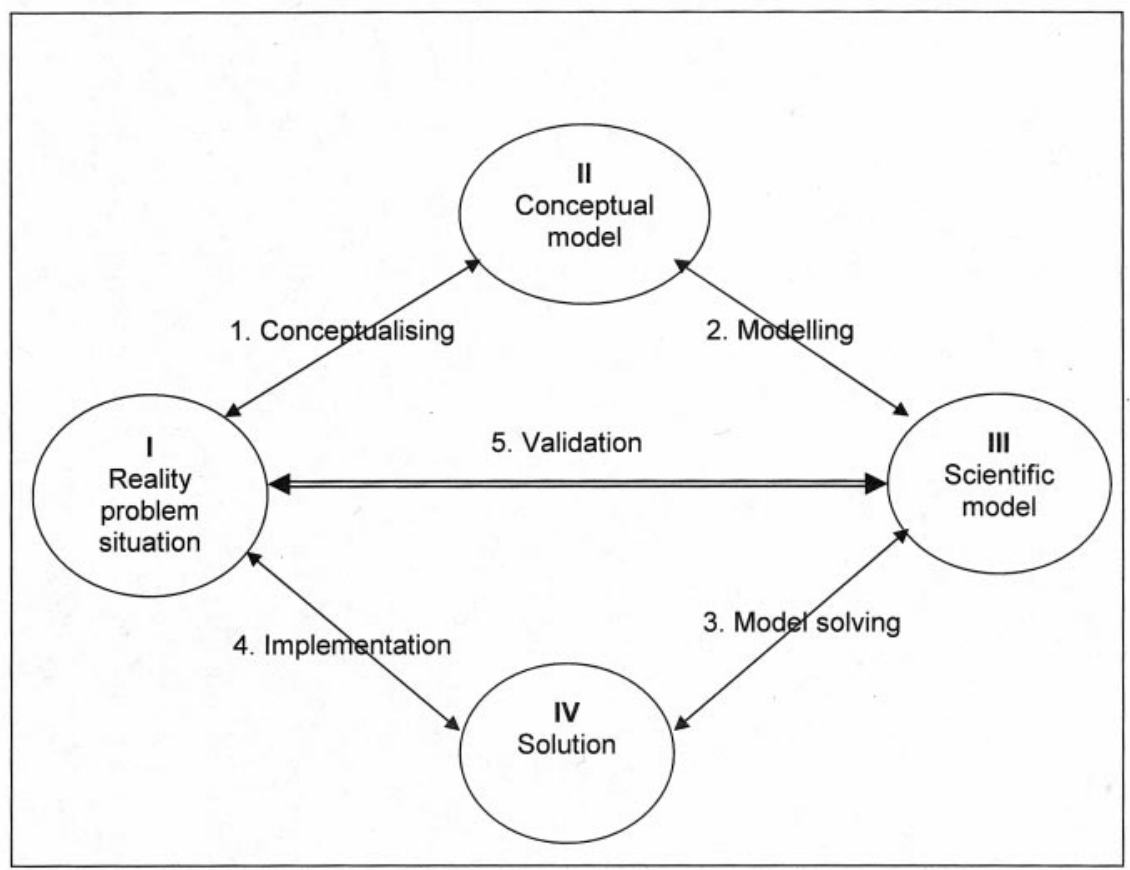

Figure 1: A system view of problem solving

\section{Reality problem situation summarised}

The reality problem situation can be summarised as being fundamentally a false epistemological concept of accounting as a discipline, which is consequently perceived as a content driven, prescriptive education practice to produce accounting technicians. The problem that needs to be solved is indeed two fold: Discovering the authentic epistemology of accounting to consequently design a paradigm for authentic learning in introductory accounting education.

\section{A conceptual model}

A qualitative phenomenological narrative inquiry is required to establish the authentic essence of accounting as reflected in its nature and structure. The result of this inquiry is the identification of the essential characteristics of accounting as the concepts which constitutes a conceptual model of the phenomenon. This involves an investigation into the ontological (the nature of reality as manifested in its essential origin) (Terre Blanche and Durrheim 1999) and epistemological (the theory of how knowledge is constructed) (Porter 1998) characteristics of the phenomenon. This second phase in this research methodology is a qualitative interpretative paradigm of discourse exploration and narrative enquiry into the formal properties of the (historical) 'story' of the origin (Bergman and Mottier 2003) of accounting. 
The phenomenological enquiry to determine the essence and the nature and structure of accounting is by tracing the phenomenon back to its very origin (Vandenberg 1995, 175-196). In very strict terms this involves a kind of thinking experiment whereby the phenomenon as it appears today is traced back in history up to the point where it, as phenomenon, 'disappears'. Immediately before the point of disappearance, is obviously the point of origin of the phenomenon. When the characteristics of the phenomenon at that point that constitute the phenomenon are identified, that would be the essence of the phenomenon.

This inquiry into accounting's essential characteristics is a qualitative, narrative description attempting to trace its historical origin. This historical origin could be ontologically established at a point in time when someone somewhere who possessed something of value to him/her, met up with someone else that needed that item. Because the item was of value to the owner, he/she did not want to simply part with it, but demanded something else of the same value in return. These items were exchanged, and although there might not have been any physical recording of the event, its significance was certainly recorded in an unintentional way, perhaps only mentally. This historical event of exchanging one item for another of equivalent value became more and more significant over time for the participants in such an exchange: at one end of the spectrum, a person may ascertain that something he/she possess (through obtaining it - like catching fish, or making it - like primitive tools) is of value for others to improve their quality of life. At the other end of the spectrum, a person who may find it difficult (for various reasons) to make or obtain an item needed to improve his/her living quality could acquire it from someone else through exchange for another item he/she possesses. This became a primary purpose of such exchange. But it became increasingly important to the owner, not only to count what is released from his/her possession, but also to account for how well value was added or at least retained through the exchange in order to maintain or improve his/her own quality of life. As the world and the people in it developed over time, these kinds of exchange transactions obviously increased in complexity, but these basic elements represent the essence of accounting: recording the value of 'possessions' and the transactions that may effect the value over time in a continual process of keeping track of the value fluctuations in order to ascertain the value added or lost at any given time. In short: The need to record in order to report. The validity of this claim could be tested in two ways: The one is to eliminate any one of the essential elements and determine whether a phenomenon without this element could function holistically as accounting. If the absent element does not alter the essential concept of accounting, then that element was not essential; if it does, however, the manipulated element was essential to accounting. The other way to establish the validity of the claim of essence is to consider any feature of modern day accounting and its association with these essential elements. If any such feature 
could not be accommodated within any of the essential elements, then the essence of accounting has not been fully established and the research process should be repeated.

It requires a critical reflection on its essence to determine the nature and structure of accounting. Such critical reflection, reveals the nature of accounting to be formulated as follows: It is a regular determining and recording of the value of 'possessions' to maintain an account of its replacement from which a continuous process of exchange of 'possessions' to improve living quality is determined.

The substantive (what: knowledge/content/product) structure (Slabbert, Van Aswegen, Fraser, Nortje and Kaske 1993, 26-27) of accounting represents the body of knowledge involved in this phenomenon and it refers to all the authentic recordings that should be done to keep track of the value of possessions at any given time. This pertains to the concepts of the need to record in order to report; the need to audit in order to trust; the need to analyse in order to understand; the need to relate in order to decide. The syntactical (how: knowledge creation/ process/method) structure (Slabbert, Van Aswegen, Fraser, Nortje and Kaske, 1993, 27-28) represents the way in which this body of knowledge is created or generated. There can be no doubt that the authentic syntactical structure of accounting arrived from a need to record, and it refers to all the 'how's' in accounting with the concepts of how to determine value, how to record value, how to best give an account of the exchange of possessions, etc.

\section{A scientific model}

The essence and the nature and structure of accounting as it was revealed through the conceptual model in the previous research phase already reveals the foundation of how it should be educated in order to result in learners becoming accountants of the highest possible quality. As has been stated before, the nature and structure of a discipline determines the way in which it should be educated: It is through the syntactical structure (the knowledge creation process) that the substantive structure (body of knowledge or product) is revealed (Schwab 1964; Slabbert and Hattingh 2005). Designing a scientific model is therefore central to the quest to design a new paradigm for accounting education. The existing substantiation of the knowledge creation process is the object of this research phase and the basis for designing powerful learning environments.

Jantsch $(1980,221)$ is very clear when he says: 'All knowledge is based on experience. In a holistic way, this experience is accessible by intuition ...'. Payne (1982, 38-44) has elaborated Kolb's well known learning cycle into the construction of different kinds of knowledge, but maintains, like Kolb, that learning starts with concrete experience. Gouws (2001) designed a model of knowledge creation in which the main features are that the learning process starts with experiencing the outer environment or reality in its events and changes. The senses, forming the border between the outer and inner environment, transforms 




Figure 2: The knowledge creation process 
the observed experience into data, and the data is transformed into information. Information derived at from the outer environment, perception as part of the inner environment and the thinking process itself all contribute to interpret the experience. This interpretation leads to understanding that enables the learner to make judgments. The result of the judgments made on an experience creates knowledge (rule, principle, method, procedure). The created knowledge, through language and communication is the source for decision-making that produces an action to influence the outer environment. This knowledge creation model can be depicted as in Figure 2.

Reflecting on the knowledge creation process, it becomes clear that it relates to learning theory in psychology and in particular educational psychology, that has become increasingly prominent because of the recognition of the importance of the brain's natural functioning in education. In this learning theory, learning is viewed as the construction of knowledge for which the brain is actually designed. This refers to constructivism (Von Glaserveld 2001, 161-173) as the paradigm within which accounting education should be conceptualized. But much more than that is the fact that humans are social beings and in that sense they also collaboratively construct meaning (Burr 1995). Socio-constructivism, as a term, covers a wide range of particular theories and '.. . it views learning as a process of construction of knowledge and skills that takes place in a social context' (Lucas and Meyer 2003, 3) Knowledge is initially created internally and subsequently through a process of interaction with the social world.

In view of the above and in relation to the problems identified with introductory accounting education earlier, it is obvious that it is dominated by the traditional approach of having theory (principles, concepts, rules, procedures) - the created subject - transmitted to learners, which they then have to apply in practice. The devastating effects of this technical-rationality paradigm of knowledge as episteme (Korthagen 2001, 10-31) are evident in the problems identified. Introductory accounting education obviously requires a fresh or alternative view of knowledge: one which recognises that accounting originated as a human activity or practice in the real world: It's education has to reflect the fact that it is therefore not a created subject but a subject to be created (Freudenthal, 1991) by the learners from their practical experience - and not academic textbook applied exercises. It is through this practical understanding or practical wisdom of accounting experiences that the contemporary knowledge as phronesis provides the insight through which knowledge as episteme (conceptual knowledge) may be constructed. This therefore constitutes an approach starting with practice and going to theory (conceptual knowledge). A comparison between knowledge as episteme and knowledge as phronesis can be found in Table 1 . 
Table 1: Types of knowledge (Korthagen 2001, 20-31)

\begin{tabular}{|c|c|}
\hline Knowledge as episteme & Knowledge as phronesis \\
\hline Expert, scientific knowledge (theory) & Individual practical knowledge \\
\hline Needs scientific understanding & Needs practical wisdom \\
\hline Knowledge of universal principals & Knowledge of concrete particulars \\
\hline Locus of certitude: Principles & Locus of certitude: Particulars \\
\hline Knowledge is conceptual & Knowledge is perceptual \\
\hline Knowledge is rigid & Knowledge is flexible \\
\hline $\begin{array}{l}\text { The principle (concept) dictates the } \\
\text { practice }\end{array}$ & $\begin{array}{l}\text { Uses the practice to discover a guiding } \\
\text { rule/principle/procedure/method }\end{array}$ \\
\hline $\begin{array}{l}\text { Knowledge learned (memorised) and } \\
\text { 'applied' }\end{array}$ & $\begin{array}{l}\text { Knowledge acquired through enough, } \\
\text { appropriate and proper experience } \\
\text { (perceiving, assessing, judging, choos- } \\
\text { ing actions, execute them, be con- } \\
\text { fronted with its consequences and } \\
\text { learn from them) }\end{array}$ \\
\hline Provides principle & Provides holistic insight \\
\hline $\begin{array}{l}\text { Teach the student concepts - avoid will, } \\
\text { emotions, etc they disturb }\end{array}$ & $\begin{array}{l}\text { Help the student see - celebrate will, } \\
\text { emotions, etc they provide insight }\end{array}$ \\
\hline
\end{tabular}

Knowledge as phronesis is concerned with the understanding of reality through experiencing reality. Practical wisdom is context-related where the contingent features of a practice are always at hand allowing principles, rules, theories and methods (conceptual knowledge) to evolve from practical realities. It should be clear that such knowledge creation process is continuous and that the quality of the (conceptual) knowledge created increases with each successive attempt as the experience of reality increase and is experienced in an interactive and collaborative context.

Smilkstein (2003) incorporated the relationship between the brain's natural functioning and education to show how to use the brain's natural learning process to create today's curricula. Claxton (1999) is very clear when he demands that learning in the natural way - as we are born to - is first and foremost a direct immersion in practical experience of reality through exploration, investigation and experimentation. This immersion provokes another of the human's natural competences and that is imagination through fantasy, visualization, and the creation of hypothetical worlds. Only then, should the possibilities thus created, be analysed by reason through the intellect to construct conceptual knowledge (rule, principle, method, etc). Since conceptual knowledge has been constructed in this way by the learner, the learner is in complete control of the knowledge constructed and could manipulate it in any way to his/her advantage. This allows the learner's intuition to use this knowledge to do something creatively new, and, in effect a 
continuous process of constructing knowledge ensues. But of crucial importance is that the knowledge constructed by the individual learner, should now be shared with peers through a process of interaction by which the constructed knowledge is assessed and through cooperative learning the learners collaboratively refines the conceptual knowledge with the aid of a facilitator of learning (an expert) to eventually achieve the highest quality of learning (constructed knowledge).

Designing the scientific model of and for introductory accounting education in this phase of the research, all the relationships between the contributions of the previous paragraphs in this section, as well as that of the conceptual model is taken into consideration. Taking the model of knowledge creation as foundation, the scientific model of and for introductory accounting education may be depicted as in Figure 3.

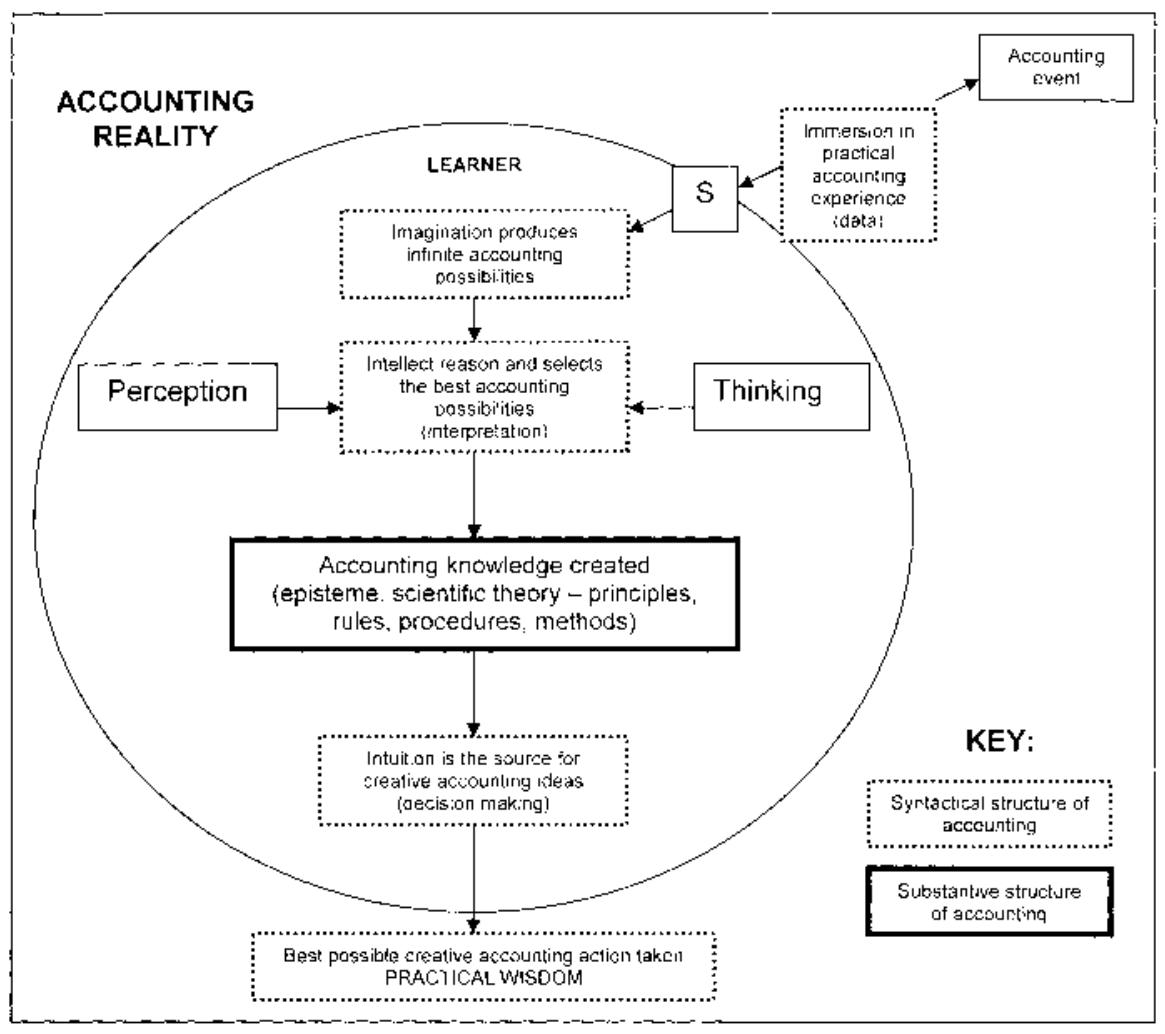

Figure 3: Conceptual model for authentic accounting education 


\section{Solution}

The point of departure in the education of introductory accounting should therefore not be conceptual knowledge because it is too abstract, stripped of all the ingredients that are in concrete experience: emotion, needs, values, character, etc. It is more important to know as much as possible about the detail of a situation. The emphasis should be on the learner who learns by constructing meaning and not simply being taught the theory and then apply it through simply following prescribed procedures.

How should the education of an introductory course of accounting be conducted? It is, as we have seen, a practical profession and not simply a system of rules and regulations. Because it is a human endeavour it is imprecise by nature, therefore the advice of Aristotle must be kept in mind. 'Every statement concerning matters of practice ought to be said in outline and not with precision, statements should be demanded in a way appropriate to the matter at hand' (Korthagen 2001, 26).

With the phronesis conception of knowledge, the learner perceives all the features of his experiences through an awareness of all the relevant particulars of a situation he judges as relevant. The lecturer should facilitate towards what the learner is aware of, what he/she sees in a problem-situation, his/her reactions, emotions, etc. The task of the lecturer is to assist the learner to become more aware of the salient features of experience, and not merely to lecture on theory, methods, or to instruct rules.

Much of what is being done in introductory accounting education - our simulated problems - have no perceptual reality, no face and no personality. The will, emotions and social responsibility of learners are central elements to knowledge. These phenomenona are currently being reviewed as hurdles towards knowledge creation. Alternately, we need concrete realities and situations to be experienced, to negotiate, to make plans, to accept responsibilities and consequences, to fail, to try again, to succeed. It is at this point where it becomes paramount to go beyond Goldberg's $(2001,319)$ question of how 'to develop courses in accounting to prepare graduates for their lifetime careers as people with broad social affinities as well as for their professional jobs'. Goldberg $(2001,320)$ also sets the vital contextual requirements for accounting courses in the following way: 'More important is its place in relevance to the social environment in which procedures are carried out. This depends on individual and social responsibility that in turn depends on a rigorous self-determination by each individual, who undertakes to practice in the field ....' This associates closely to the Generally Accepted Accounting Principles (GAAP) which is rooted in experience: practical necessity and procedures necessary to define accepted accounting practice (AICPA 1970). The fact that accounting principles are rooted and started in doing accounting in the field, makes the accounting experience real and not based on artificial imitation of the accounting reality. And when learning is involved, 
Jantsch $(1980,171)$ reminds us that 'True learning is never rote learning, but always stimulated experiences by oneself'. The primary problem with accounting education is that the numbers and figures that we use to simulate reality do not have any empirical referents. Sterling, $(1979$, xii) echo this sentiment when he says that 'The development of accounting thought has been restricted by an essentially constraint on its empirical domain'. The reason why the artificial reality is ill suited for learning quality is because it lacks the necessary relationships to create meaning. 'Relationships are all there is to reality' (Wheatley 34). Accounting represents a world of process; a process of connectivity where business transactions come into existence because of relationships through which meaning is constructed .

The learner should become part of the accounting reality - part of real life. This pertains to constructivist learning (Wilson 1996) which requires the design of powerful learning environments for the highest possible quality of learner learning. De Corte (2003, 21-33) describes powerful learning environments as environments that best enhances transfer of learning. Van Merriënboer and Paas (2003, 328) reports that real-life has become the dominant consideration in designing powerful learning environments. In fact, they say that 'learning needs to be situated in problem solving in real life, authentic contexts' (Van Merriënboer and Paas 2003, 5), where the environment contains ill structured information in which no answers are embedded, but it requires engagement of the learner through meaningful experiences which enables 'the learner to learn the ways of knowing of an expert' (Van Merriënboer and Paas 2003, 5). Claxton (1999, 307-311) echoes the same notion and adds the crucial importance that learning to learn (metalearning through metacognition) includes the self discovery of the tools (algorithms) to solve problems and the discovery of the relevance of the application of such tools (Claxton 1999, 198-211). De Corte $(2003,25)$ suggests that the acquisition of such competencies requires that learners be confronted as much as possible with challenging, real life problems in authentic contexts that has personal meaning for them which they need to solve personally and through interaction and collaboration that immediately situates the learning that is required by powerful learning environments in a socio-constructivist paradigm.

The example that follows attempted at incorporating most of the contemporary instructional design and psychological components and dimensions with less emphasis on the technology components and dimensions (De Corte, Verschaffel, Entwistle and Van Merriënboer 2003)

\section{AN EXEMPLAR OF A POWERFUL LEARNING ENVIRONMENT}

At first glance, the suggestion may seem at least somewhat impractical, while others may deem it outright stupendous. What is however important is whether we are serious about dislodging accounting education from its debilitating shackles? Goldberg $(2001,320)$ is very explicit in the fact that achieving this would demand 
'ensuring that educators and researchers have freedom to experiment ...'. If this is our attitude then judgement of the suggestion should be replaced by the question: How could we make it possible? It is from this viewpoint that this suggestion is presented.

To start off with, learners do not need to possess any knowledge of accounting. They should be confronted with a learning task. A learning task is a real life problem that the learners need to solve themselves. The following may be a suggestion for such a learning task. Of course the particulars should be adjusted to suit the specific context.

Find yourself a one-man business (or spaza shop or informal open/flea market/street vender kind of business) in close proximity of your dwelling place, operating on a street for at least 5 days of the week from a temporary facility, dealing in a minimum of commodities of whom the clients are the pedestrians or passers by. Introduce yourself and offer your services to do the bookkeeping of the business for one month. The sole purpose for doing this would be to enable you to generate suggestions for the best ways in which the profit of the business could increase to as much as 30 per cent within the next 6 months. For this month you have no class to attend at the university, but you will visit your businessperson every business day to (a) make as much thorough observations and recordings about the business, its environment, clients, the way it operates, etc and (b) you need to keep a very thorough and detailed daily record of all business taking place for that month and record a complete statement of business for each day. Before you leave your businessperson at the end of that month, you will provide him/her with a detailed record of the financial position comparing the beginning and the end of that month's activities.

Arriving back at the university, what the learners have produced during the preceding month should serve as their learning material for an extended period of time. Defending that material through critical assessment against the multitude of experiences of all the learners, against other existing practices as well as other existing accounting theory. Through interaction during cooperative learning, this critical assessment process should be maintained to refine the constructed (conceptual) knowledge. This process should be facilitated by Honors and/or Master's learners as experts into the highest quality knowledge product with the aid of appropriate technology where appropriate and necessary. Because the learning task is set within a holistic, challenging, real life, authentic context, the learner inadvertently learns everything needed to operate creatively and appropriately towards the highest quality - and of course accuracy - of accountancy through becoming a reflective practitioner.

Reflecting on this learning task executed under the conditions of a powerful learning environment, it should be obvious that the holistic learning quality of this 
paradigm is virtually unsurpassable: from acute observation, accurate calculation and reporting to team work, effective communication and handling ethical issues with integrity.

\section{CONCLUSION}

Accounting lecturers need to be reminded that they are in the knowledge creation business. This means that our task is to maximize the potential of the accounting learner in a holistic integrated way, also working with the souls of learners and not only with accounting as a prescribed practice. Accounting is only a vehicle for professional and personal growth.

For accounting education, the development of phronesis is most important. Consequently the learning of learners start from real life experiences. The goal of powerful learning environments in accounting education is to enable learners to become effective holistic accountants.

\section{REFERENCES}

Accounting Education Change Commission. 1990. Objectives of education for accountants. Issues is Accounting Education 6 (2): 307-312.

American Accounting Association. 1990. Committee on the future structure, content and scope of accounting education. Issues in Accounting Education 6 (1): 108 - 195.

Ansari, S., J. Bell, T. Klammer and C. Lawrence. 1997. Strategy and management accounting. New York: Irwin.

Beaver, W. H. 1992. Challenges in accounting education. Issues in Accounting Education 7 (2): 135-143.

Bereiter, C. and M. Scardamalia. 2003. Learning to work creatively with knowledge. In Powerful learning environments: Unraveling basic components and dimensions, eds. E. de Corte, L. Verschaffel, N. Entwistle and J. van Merriënboer, 57-68. Oxford: Pergamon.

Bergman, M. and V. Mottier. 2003. Discourse and narrative analysis: Interpretative methodologies for analyzing text and talk. Unpublished course material. University of Cambridge, UK and University of Lausanne, Switzerland.

Burr, V. 1995. An introduction to social constructionism. London: Routledge.

De Corte, E. 2003. Designing learning environments that foster the productive use of acquired knowledge and skills. In Powerful learning environments: Unraveling basic components and dimensions, eds. E. de Corte, L. Verschaffel, N. Entwistle and J. van Merriënboer, 21-33. Oxford: Pergamon..

Claxton, G. 2000. Wise up: The challenge of lifelong learning. London: Bloomsbury.

Freudenthal, H. 1991. Revisiting mathematics education. Dortrecht: Kluwer.

Goldberg, L. 2001. A journey into accounting thought. London: Routledge.

Gouws, D. G. 1997. Perspectives surrounding accounting communication. Meditari Accounting Research 5 (1): 61-82.

Gouws, D. G. and W. Bosua. 1997. The tuition of accounting at tertiary institutions measured against the Beard tuition model and practice needs. Meditari Accounting Research 5 (2): 54 62 .

Gouws, D. G. and P. Lucouw. 1999 The process beyond the numbers and ratios. Meditari Accounting Research 7 (1): 99-122. 
Gray, R. and J. McKernan. 2002. Accounting education: Crisis? What crisis? Accounting and Finance Update 5 (2): 9-11.

Habermas, J. 1972. Knowledge and human interest. London: Heineman.

Holland, J. H. 1992. The global economy as an adaptive process. In Complexity: The emerging science at the edge of order and chaos, ed. M. M. Waldrop, 63-78. New York: Simon and Schuster.

Hulme, R. D., K. B. Ehrenreich and D. F. Putnam. 1997. Implementing the user approach in accounting courses. The Cal Poly Pomona Journal of Interdisciplinary Studies 10: 141-155. Available at: http://www.csupomona.edu/ jis/1997/Hulme.pdf. Retrieved on 29 June 29, 2005.

Jantsch, E. 1980. The self-organizing universe: Scientific and human implications of the emerging paradigm of evolution. New York: Pergamon Press.

Korthagen, F. A. J. 2001. Linking practice to theory: The pedagogy of realistic teacher education. Mahwah: Lawrence Erlbaum Associates.

Lehtinen, E. 2003. Computer-supported collaborative learning: An approach to powerful learning environments. In Powerful learning environments: Unraveling basic components and dimensions, eds. E. de Corte, L. Verschaffel, N. Entwistle and J. van Merriënboer, 35-53. Oxford: Pergamon.

Littlejohn, W. L. 1989. Theories of human communication. (Third Edition) Belmond: Woolsworth Publishing Company.

Lucas, N. and H. F. Meyer. 2003. Understanding students' conception of learning and subject in introductory courses: Accounting. Paper read at the European Association for Research on Learning and Instruction. Padova: Italy.

Milacek, E. and C. P. Allen. 1992. Does more mean better? Management Accounting July 1992:56-58.

Mitroff, I. I., F. Betz, L. R. Pondy and F. Sagasti. 1974. On managing science in the systems age: two schemes for the study of science as a whole systems phenomenon. Interfaces 4 (3): 46-58.

Nonaka, I. 1998. The Knowledge Creating Company. In Havard Business Review on Knowledge Management, 79-91. Harvard: Harvard Business School Press.

Payne, R. L. 1982. The nature of knowledge and organizational psychology. In The theory and practice of organizational psychology, eds. N. Nicholson and T. D. Wall, 37-67. London: Academic Press.

Pfenninger, K. H. 2001. The evolving brain. In The origins of creativity, eds. K. H. Pfenninger and V. R. Shubik. New York: Oxford Diniventity Press.

Porter, E. 1998. Epistemology and research. Deakin University, Faculty of Arts, Online publication. Available at: http://rrh.deakin..edu.au/articles/subviewnew.asp?ArticleID=124.

Rodgers, W. 1997. Throughput modeling: Financial information used by decision makers. Greenwich: Jai Press.

Ryan, B., R. W. Scapens and M. Theobold. 1992. Research method and methodology in finance and accounting, London: Academic Press.

Schwab, J. J. 1964. The structure of knowledge and the curriculum. Chicago: Rand McNally. Simon, H. A. 1982. The sciences of the artificial. (Second edition). Boston: MIT Press.

Slabbert, J. A., I. S. van Aswegen, W. J. Fraser, T. Nortje and L. E. M. E. Kaske. 1993. Biology teaching: An information and study manual for students and teachers. Acacia, Pretoria.

Slabbert, J. A. 1997. Maximising human potential through facilitating lifelong learning. Unpublished manuscript. Pretoria: University of Pretoria. 
Slabbert, J. A. and A. Hattingh. 2005. Where is the postmodern wisdom we have lost in reductionist knowledge: A curriculum's epitaph. Journal of Curriculum Studies (in press).

Smilkstein, R. 2003. We're born to learn: Using the brain's natural learning process to create today's curriculum. Thousand Oaks CA: Corwin Press.

Stent, G. S. 2001. Meaning in art and science. In The origins of creativity, eds. K. H. Pfenninger and V. R. Shubik, 31-42. New York: Oxford Diniventity Press.

Stevens, C. F. 2001. Line versus color: The brain and the language of visual arts. In The origins of creativity, eds. K. H. Pfenninger and V. R. Shubik, 177-189. New York: Oxford Diniventity Press.

Stark, R. H. D. 1983. Management principles and practice. A cybernetic approach. New York: Gorden and Breach Science Publishers.

Terre Blanche, M. and K. Durrheim. 1999. Research in practice: Applied methods for social sciences. Cape Town: University of Cape Town Press.

Vandenberg, D. 1995. Phenomenology in education discourse. In Metatheories in philosophy of education, ed. P. Higgs, 175-196. Johannesburg: Heinemann.

Von Glaserveld, E. 2001. Radical constructivism and teaching. Prospects 31 (2): 161-173.

Von Merriënboer, J. J. G. and F. Paas. 2003. Powerful learning and the many faces of instructional design: Towards a framework for the design of powerful learning environments. In Powerful learning environments: Unraveling basic components and dimensions, eds. E. de Corte, L. Verschaffel, N. Entwistle and J. van Merriënboer, 3-20. Oxford: Pergamon.

Waldrop, M. M. 1992. Complexity: The emerging science at the edge of order and chaos. New York: Simon and Schuster.

Wheatley, M. J. 1999. Leadership and the new science: discovering order in a chaotic world. San Francisco: Berret-Koehler Publishers.

Wilson, B. 1996. Constructivist learning environments. Newbury Park, CA: Sage Publications. 